\title{
Diabetic retinopathy: quantitative variation in capillary basement membrane thickening in arterial or venous environments
}

\author{
A W Stitt, H R Anderson, T A Gardiner, D B Archer
}

\begin{abstract}
Diabetes mellitus was induced in male beagles by a single injection of an alloxan and streptozotocin cocktail and fasting blood sugar levels maintained between 15 and $20 \mathrm{mmol} /$. Five years after induction of diabetes, three diabetic animals were sacrificed, together with sex and age-matched controls, and the retinas fixed for either transmission electron microscopy (TEM) or trypsin digestion. In TEM specimens, capillaries in close proximity to the major vessels were designated as either $\mathbf{A E}$ (arterial environment) or VE (venous environment) and the thickness of their basement membranes (BMs) measured using an image analyser based two dimensional morphometric analysis system. Results show that the BMs of retinal capillaries from the diabetic dogs were significantly thicker than those from control dogs. Furthermore, within the diabetic group the AE capillaries had thicker BMs than VE capillaries $(p \leqslant 0.05)$. The controls, however, showed no significant difference in BM thickness between $\mathrm{AE}$ and $\mathrm{VE}$ capillaries. Although many of the capillaries designated as AE or VE would actually have been derived from the opposite side of the circulation, with respect to BM thickness, they conformed to values of their specific group. The conclusion is that diabetic capillaries are more vulnerable to $\mathbf{B M}$ thickening in an arterial environment than in a venous environment.
\end{abstract}

(Brf Ophthalmol 1994; 78: 133-137)

It is now established that the diabetic dog develops a retinopathy that is morphologically identical to the preproliferative changes observed in the human retina. ${ }^{12}$ The various pathological manifestations of this condition, such as microaneurysms, zones of capillary nonperfusion, pericyte cell death, and thickening of vascular basement membranes (BM) have been consistently reported in this animal model..$^{3-5}$ Of all these changes, $\mathrm{BM}$ thickening has received most attention, being the major and earliest morphological characteristic of diabetic microangiopathy, not only in the retina, ${ }^{6-8}$ but in the kidneys, ${ }^{10}$ muscle, ${ }^{11}$ and skin $^{12} 13$ of humans and diabetic animals.

Several studies have sought to measure BM thickening of the retinal capillaries and have quantitatively confirmed BM thickening during diabetes. ${ }^{14-17}$ Despite this, it remains unknown if $\mathrm{BM}$ thickening is more marked in any particular portion of the retinal circulation. Ashton ${ }^{18}$ suggested that increased mural thickening occurs at the arterial side of the circulation in diabetics, particularly affecting the precapillary arterioles. Also, workers in our laboratory have previously observed localised capillary BM thickening within the diabetic retina, with vessels showing grossly thickened BMs occurring in the same capillary bed as vessels in which the BM thickness was within normal limits. ${ }^{19}$ The subjective impression in this study was that BM thickening was greater in capillaries situated close to arteries than in those close to veins.

In the present study we have investigated, quantitatively, the possibility of a difference in BM thickness between capillaries residing in tissue environments dominated by either major retinal arteries or veins.

\section{Materials and methods}

Male beagle dogs were made diabetic with a cocktail of streptozotocin and alloxan according to Anderson et al..$^{20}$ They were maintained as moderate diabetics with fasting blood sugars between 15 and $20 \mathrm{mmol} / 1$. Blood glucose levels were monitored daily and regulated with a single daily injection of Insulatard isophane insulin (20-40 units/day) given subcutaneously before breakfast.

Age and sex-matched control dogs were also maintained under identical conditions to the diabetics. After 5 years' duration of diabetes, three diabetic animals and three controls were sacrificed and the right eye of each processed for trypsin digest examination according to the method described by Kuwabara and Cogan. ${ }^{21}$ The digests were stained with periodic acid Schiff and haematoxylin.

Following removal of the anterior segment and vitreous, the left eye cup was fixed for transmission electron microscopy (TEM) by overnight immersion in $2.5 \%$ glutaraldehyde in $0.1 \mathrm{M}$ cacodylate buffer containing $10 \mathrm{mmol}$ magnesium chloride. Tissue blocks straddling the main blood vessels in the central retina were dissected out, post fixed in osmium tetroxide, dehydrated, and embedded in Spurr's resin. Ultrathin sections were stained with uranyl acetate and lead citrate before examination in the electron microscope.

The criteria for selecting capillaries were the presence of a single discontinuous layer of pericytes and no more than three endothelial cell junctions per vessel profile. These were deemed more reliable criteria than size alone, since they allowed exclusion of capillary sized arterioles. All the retinal capillaries observed in close proximity $(60-80 \mu \mathrm{m})$ to the major vessels were designated as AE - that is, from an arterial environment, or VE, from a venous environment 


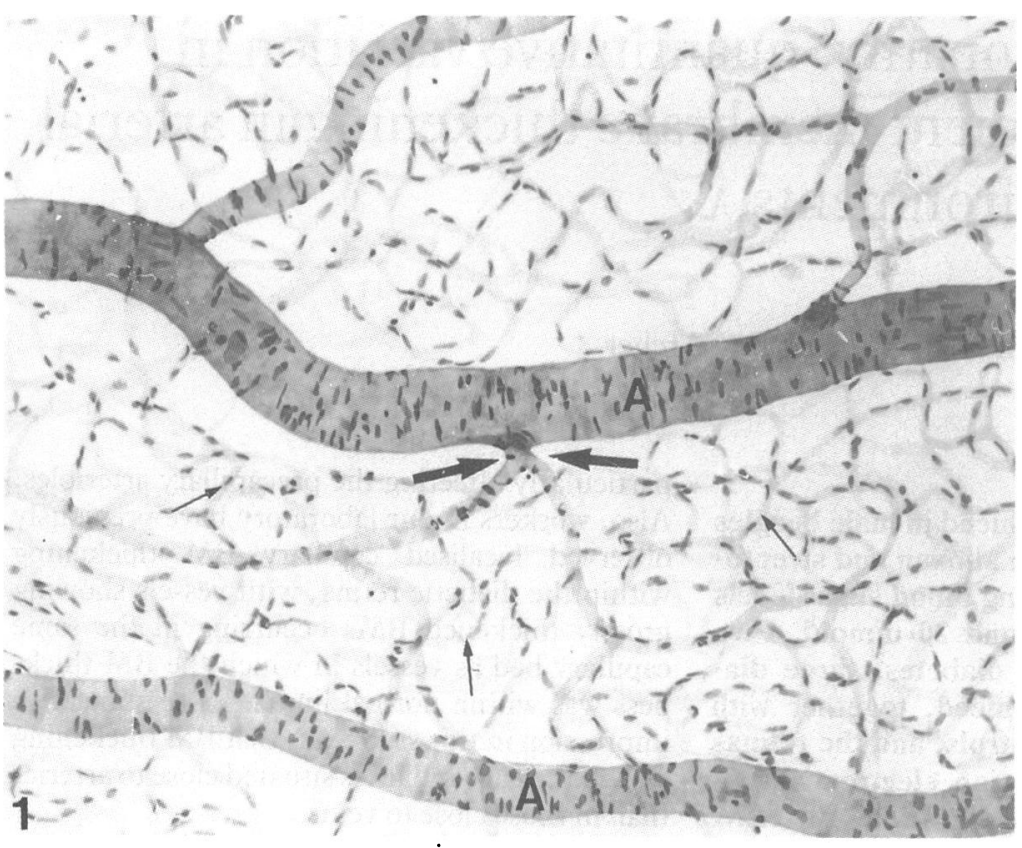

Figure 1 Trypsin digest from a normal dog showing that the capillaries (small arrows) lying between adjacent arteries $(A)$ or between an arteriolar bifurcation (large arrows) are derived predominantly from the associated major vessel (magnification $\times 250$ ).

Figure 2 Trypsin digest from a normal dog showing retinal veins (large arrows) with a considerable overlap of small arterioles and arterial capillaries (small arrows) (magnification $\times 250$ ). (see rationale for capillary designation below) and it was also noted if they occurred in the outer plexiform layer or inner plexiform/nerve fibre layer of the retina. Capillaries were then photographed at magnifications ranging from 70009000 , the images transferred to an image analysis system (Fenestra, Confocal Technologies Ltd, Liverpool), and calibrated according to magnification. The two dimensional thickness of the BM of each capillary was measured by randomly placing a grid over each image and, at sites where the $B M$ was intercepted by a grid line, the shortest distance across the BM was measured. Around 25-30 measurements of BM thickness were made per capillary and from these the mean BM thickness for every capillary sampled was calculated. For each dog, the capillaries measured were taken from TEM blocks from five different regions of central retina. Within the diabetic group of dogs a total of 41 capillaries

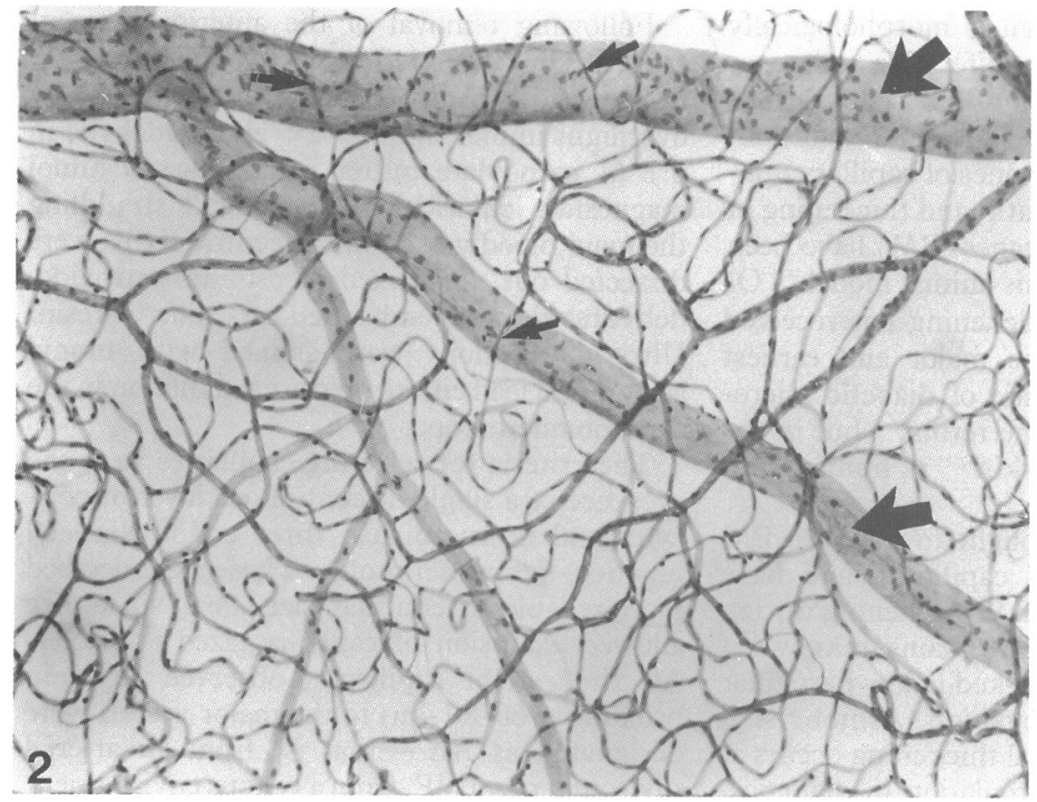

were measured; 26 were $\mathrm{AE}$ and $15 \mathrm{VE}$, and for the control group of dogs 77 capillaries were analysed comprising $48 \mathrm{AE}$ and 29 VE. Vessels which had lost their pericyte covering were excluded from the quantitative study. The results were analysed by a two level nested analysis of variance (ANOVA) and also by a two way ANOVA with replication. To ensure that an adequate number of capillaries had been sampled, graphs of the cumulative means for capillary BM thickness were plotted.

\section{Capillary designation}

Trypsin digests show that in comparison with the regular arrangement of alternating arteries and veins found in animals such as the rat, the retinal vasculature in the dog is highly asymmetrical. While there is a relatively regular pattern in the equatorial to peripheral retina, with considerable arteriovenous overlap, major portions of the central retina are dominated by arteries and arterioles, with little venous overlap. As a consequence of this arrangement, capillaries lying between adjacent arterioles or between arteriolar bifurcations in the central retina tend to be derived from the associated major vessel (Fig 1). In contrast, the major veins in the central retina are heavily overlapped by arterioles and their capillaries (Fig 2). It was therefore decided to sample capillaries adjacent to either the major arteries or veins in the expectation that a sufficiently large sample would expose any real difference in BM thickness between the two groups.

\section{Results}

\section{TRYPSIN DIGESTS}

Following 5 years of diabetes in dogs, trypsin digest preparations revealed numerous pericyte ghosts in the retinal capillaries, although acellular capillaries were rare and microaneurysms were not observed. In terms of gross architecture and layout, there were no significant differences between normal and diabetic dogs in the time period covered by the present study.

\section{TRANSMISSION ELECTRON MICROSCOPY}

AE capillaries in diabetic dogs displayed markedly thickened BMs compared with $\mathrm{AE}$ capillaries in control animals (compare Figs 3 and 4). VE capillaries from diabetics also showed increased BM thickening (Fig 5) when compared with control capillaries. The most extreme BM thickening occurred in diabetic AE capillaries with no pericyte covering although such vessels were excluded from the quantitative study.

Mean values of two dimensional BM thickness $(\mu \mathrm{m})$ of $\mathrm{AE}$ and VE capillaries from control and diabetic dogs are presented in Table 1. A two way ANOVA carried out on these data showed that the BMs of retinal capillaries from the diabetic dogs were significantly thicker than those from the control animals $(p \leqslant 0.005)$ (Fig 6).

Within the diabetic group, a two level nested ANOVA showed that AE capillaries had significantly thicker BMs than VE capillaries $(p \leqslant 0.01)$ 


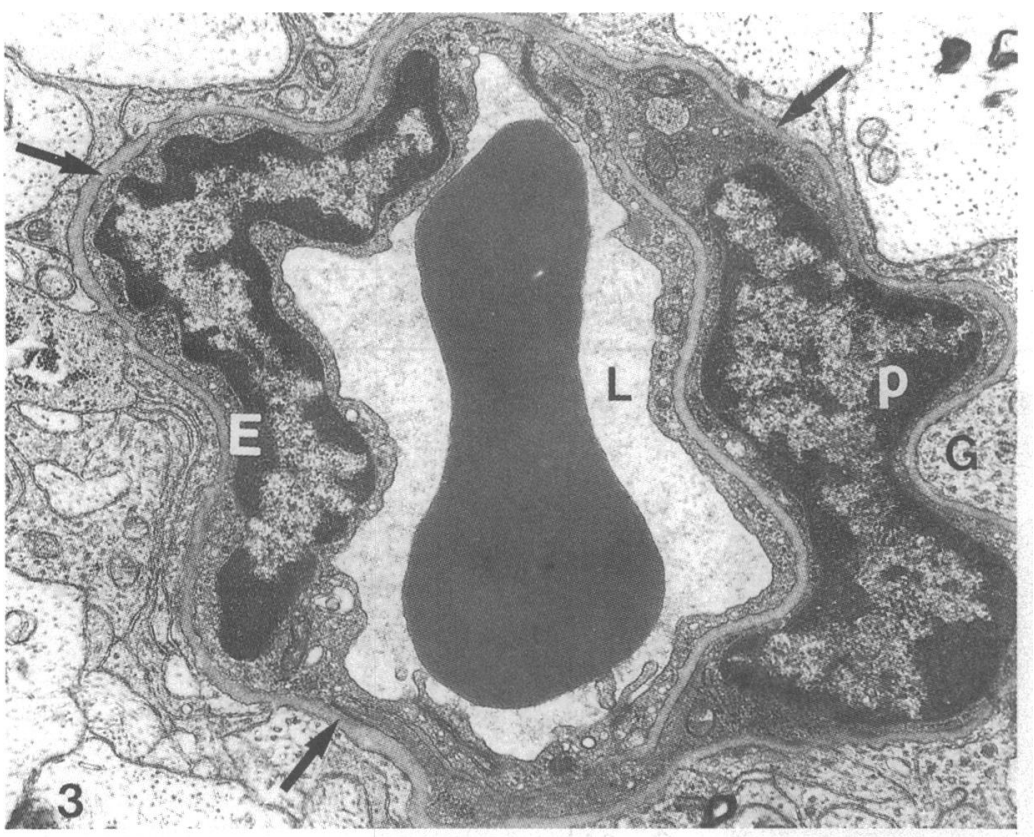

Figure 3 Transmission electron micrograph of a retinal capillary from $a$ control dog showing an endothelial cell $(E)$, pericyte $(P)$, and basement membrane (arrows). $L=$ lumen, $G=$ glial cell (magnification $\times 9000)$.

Figure 4 Transmission electron micrograph of an arterial environment capillary from a 5 year diabetic dog showing the thickened basement membrane (arrows). $E=$ endothelial cell, $P=$ pericyte, $L=$ lumen (magnification $\times$ 9000). reported lesion of diabetic microangiopathy, being observed consistently in human diabetes and experimental diabetes in several different animal models. That microaneurysms were not encountered in the present study was attributed to the moderate diabetic state, breed, and environmental conditions of the animals. Although it is known that development of thickened BMs is related to prolonged hyperglycaemia, ${ }^{22-24}$ the pathogenesis of this phenomenon remains to be elucidated adequately. The current investigation has shown that after 5 years of diabetes in dogs, BM thickening is more marked in capillaries, when residing in an environment dominated by a major arterial vessel. Vessels in venous environments were still thicker than nondiabetic equivalents. The phenomenon of vessels with grossly thickened BMs resident in the same capillary bed as others with BMs within the normal range has been previously observed but not quantified. ${ }^{19}$

There has been much speculation about the causal factors of $\mathrm{BM}$ thickening in diabetic capillaries and it has been proposed that excessive polyol pathway activity leading to damaging accumulations of intracellular polyalcohols in vascular cells may account for increased biosynthesis of BM components. ${ }^{25-28}$ Others have emphasised increased non-enzymatic glycosylation of BM components in diabetes. ${ }^{29-31}$ Glycosylated collagens and other $\mathrm{BM}$ proteins are known to be less susceptible to protease digestion which may reduce $\mathrm{BM}$ modification by vascular cells and lead to a net increase in BM thickness in diabetes. ${ }^{32} 33$ There is also evidence for reduced activity of enzymes involved in BM catabolism $^{34}$ and increased activity of enzymes involved in $\mathrm{BM}$ synthesis. ${ }^{35}{ }^{36} \mathrm{BM}$ proteins may also be altered through oxidative damage by free radicals generated by the autoxidation of glucose or glucose protein adducts ${ }^{37-41}$ and this, in combination with compromised scavenger systems, may increase the free radical induced modifications of BM components in diabetes. ${ }^{42}$

Owing to the degree of arteriovenous overlap in the retinal circulation of the dog, not all of the capillaries, designated either $\mathrm{AE}$ or VE for the purposes of the present study, were truly arterial or venous in terms of their distance from a precapillary arteriole or a postcapillary venule. It was therefore surprising that the thickest BMs in the VE group were never greater than the thinnest in the $\mathrm{AE}$ group. Considering the inevitability of arteriovenous overlap, if the BM thickness was related to the distinctive arterial or venous nature of the vessel, it would be expected that the AE group would include some vessels with a BM thickness approaching the greatest value recorded for the VE group and vice versa. However, the greatest value recorded for BM thickness in the venous group was less than the smallest recorded for the arterial group. Accordingly, it would appear that venous capillaries suffer more BM thickening when resident in an arterial environment while arterial capillaries suffer less in a venous environment.

As BM thickening in diabetes has been related to hyperglycaemia, ${ }^{22}$ it could be speculated that the differential BM thickening in the present study is associated with the relative concentra- 
Table 1 Mean two dimensional values of capillary basement membrane (BM) thickness for normal and diabetic dogs. The results are presented as mean $B M$ thickness values $(\mu m)$ for all capillaries measured (value shown in bold with $S D$ ) and also, for capillaries appearing in the outer and inner retinal layers. The proportion of inner and outer capillaries for each group appears in brackets

\begin{tabular}{|c|c|c|c|c|c|c|}
\hline & \multicolumn{3}{|c|}{ Diabetic capillaries } & \multicolumn{3}{|c|}{ Control capillaries } \\
\hline & $\begin{array}{l}\text { Overall mean } \\
\text { thickness }(\mu m)\end{array}$ & $\begin{array}{l}\text { 'Outer' } \\
\text { capillaries }\end{array}$ & $\begin{array}{l}\text { 'Inner' } \\
\text { capillaries }\end{array}$ & $\begin{array}{l}\text { Overall mean } \\
\text { thickness }(\mu m)\end{array}$ & $\begin{array}{l}\text { 'Outer' } \\
\text { capillaries }\end{array}$ & $\begin{array}{l}\text { 'Inner' } \\
\text { capillaries }\end{array}$ \\
\hline $\begin{array}{l}\text { Arterial environment capillaries } \\
\text { Venous environment capillaries }\end{array}$ & $\begin{array}{l}0.258(0.148) \\
0.173(0.055)\end{array}$ & $\begin{array}{l}0.248(52 \cdot 4 \%) \\
0 \cdot 171(47 \cdot 6 \%)\end{array}$ & $\begin{array}{l}0 \cdot 268(47 \cdot 6 \%) \\
0 \cdot 175(52 \cdot 4 \%)\end{array}$ & $\begin{array}{l}0.142(0.036) \\
0.152(0.332)\end{array}$ & $\begin{array}{l}0 \cdot 138(33 \cdot 3 \%) \\
0 \cdot 141(42 \cdot 8 \%)\end{array}$ & $\begin{array}{l}0.146(66 \cdot 7 \%) \\
0.163(57 \cdot 2 \%)\end{array}$ \\
\hline
\end{tabular}

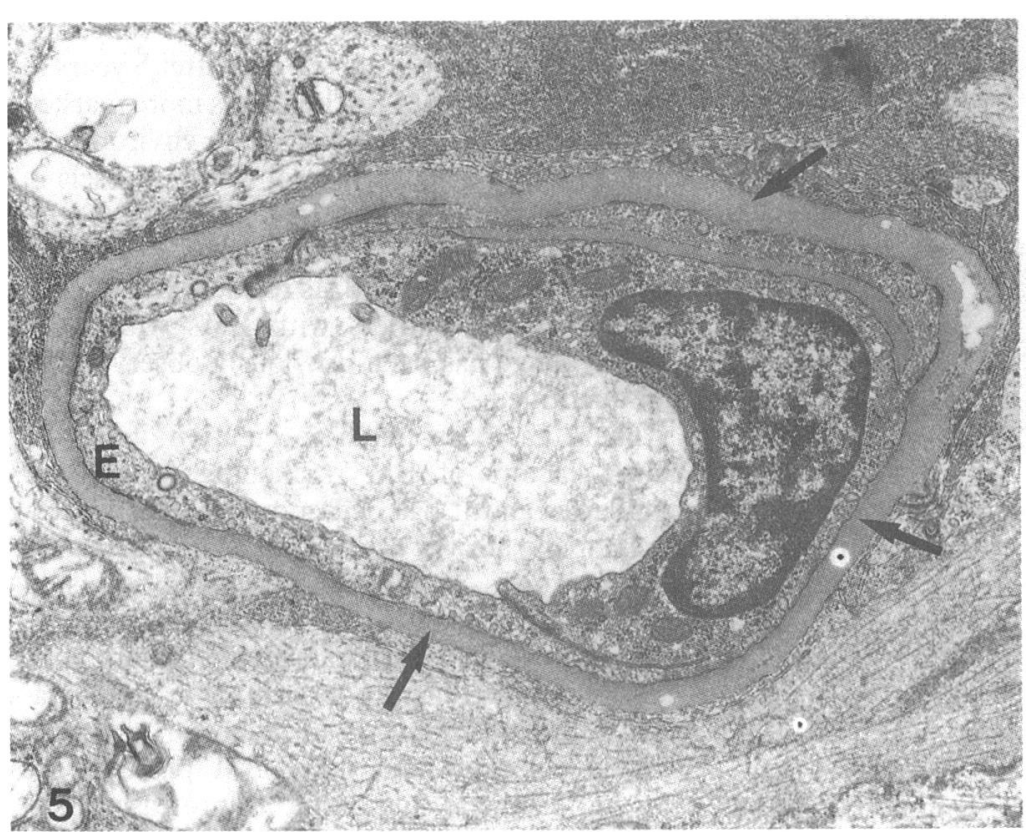

Figure 5 Transmission electron micrograph of a venous environment capillary from a 5 year. diabetic dog. Note that the thickening of the basement membrane (arrows) is not as extreme as in the arterial environment capillary. $E=$ endothelial cell, $L=$ lumen (magnification $\times 9000$ ).

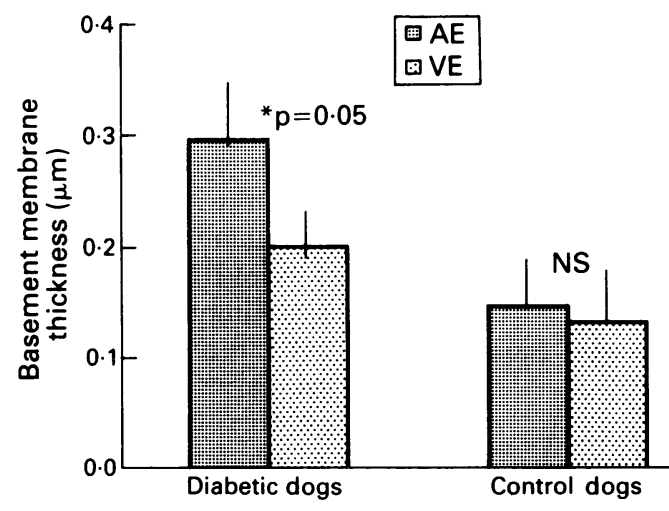

Figure 6 Graph showing the basement membrane thickness of $A E$ and VE designated capillaries in diabetic and control dogs. Means $(S D)$ are indicated. ( $A E=$ capillaries in an arterial environment; $V E=$ capillaries in a venous environment.)

tions of glucose in the arterial or venous environments. However, at present, it is not known if such a gradient exists in the retina during chronic hyperglycaemia. It is also possible that the differential capillary BM thickening in the diabetic animals may be related to the tissue oxygen tension and increased oxidative stress in the arterial regions. Oxygen tension in the retinal neuropile of the pig is known to be higher in the vicinity of retinal arterioles than in the remainder of the extracellular space of inner retina..$^{43}$ Also, the high tissue oxygen tension in the juxtaarteriolar region is reflected by the capillary-free zone around the arterioles in human retina.
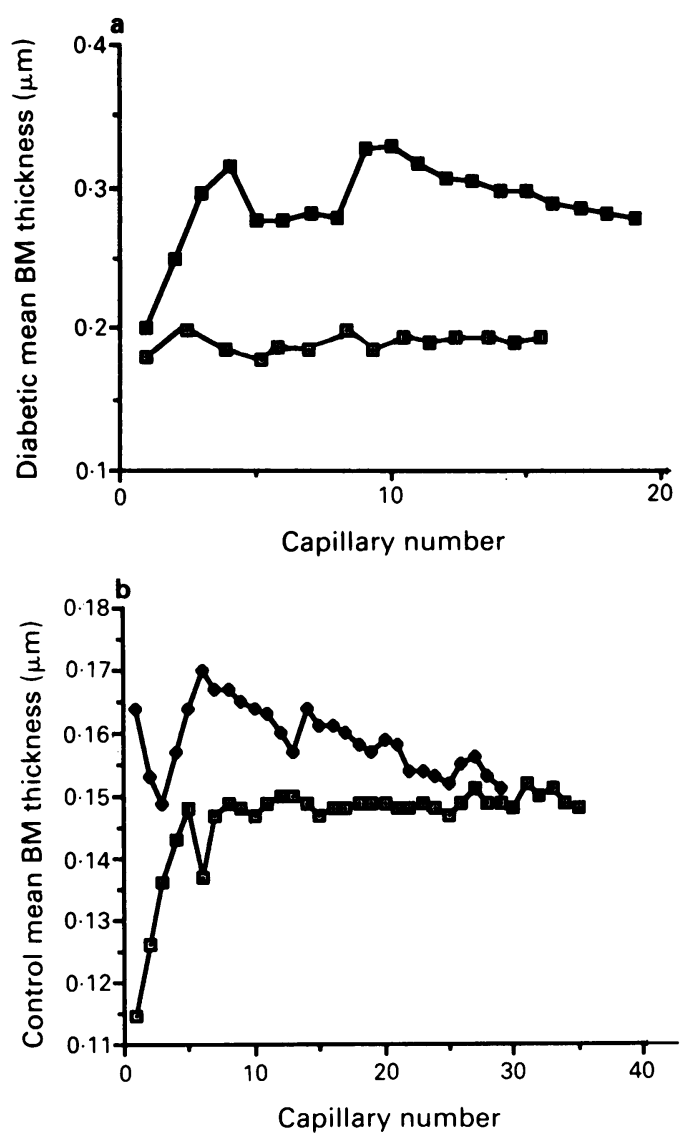

Figure 7 Plots of running means for capillary basement membrane $(B M)$ thickness from $(a)$ diabetic dogs and $(b)$ control dogs. (口) Arterial environment capillaries; ( $\square$ ) venous environment capillaries.

Table 2. Results from a two way ANOVA showing comparison between diabetic and normal and between arterial environment $(A E)$ and venous environment $(V E)$ capillaries

\begin{tabular}{lrllc}
\hline Source of variation & \multicolumn{1}{l}{ df } & \multicolumn{1}{l}{ SS } & $M S$ & \multicolumn{1}{l}{$F$} \\
\hline Subgroups & 3 & 0.545 & $0 \cdot 1812$ & \\
A(diabetics/controls) & 1 & 0.31 & 0.31 & $21 \cdot 15^{\star \star \star}$ \\
B(AE/VE capillaries) & 1 & $0 \cdot 1038$ & $0 \cdot 1038$ & $7 \cdot 08^{\star \star}$ \\
A $\times$ B interaction & 1 & 0.1312 & 0.1312 & $8.95^{\star \star \star}$ \\
Within groups (error) & 248 & 3.63624 & 0.01466 & \\
Total & 251 & 1.98175 & & \\
\hline
\end{tabular}

$F 0.01(1,248)=6 \cdot 63^{\star \star} ; F 0.005(1,248)=7 \cdot 88^{\star \star \star}$.

However, it has recently been suggested that the combination of glycation and oxidation, a phenomenon described as 'glycoxidation', may be more important in protein modifications of the extracellular matrix occurring in diabetes than either process alone. ${ }^{44}$ Therefore, increased BM thickening of retinal capillaries residing in arterial environments, as described in the present study, may result from a complex interplay between hyperglycaemia and enhanced oxidation in such environments. 
This investigation was supported by a grant from the Guide Dogs for the Blind Association.

1 Engerman R, Bloodworth JMB, Nelson S. Relationship of microvascular disease in diabetes to metabolic control. Diabetes 1977; 26: 760-9.

2 Black HE, Rosenblum IY, Capen CC. Chemically induced (streptozotocin-alloxan) diabetes mellitus in the dog. $A m \mathcal{F}$ Pathol 1980; 98: 295-305.

3 Engerman RL. Animal models of diabetic retinopathy. Am Acad Ophthalmol Otol 1976; 81: 710-8.

4 Engerman R, Finkelstein D, Aquirre G, Diddie KR, Fox RR, Frank RN, et al. Animals appropriate for studying diabetes mellitus and its complications: ocular complications. mellitus and its complit $1982 ; 31: 82-8$.

5 Engerman RL, Kern TS. Progession of incipient diabetic retinopathy during good glycemic control. Diabetes 1987; 36: 808-12.

6 Leuenberger P, Cameron D, Staffacher W, Renold AE, Babel J. Ocular lesions in rats rendered chronically diabetic with streptozotocin. Ophthalmol Res 1971; 2: 189-204.

7 Williamson JR, Kilo C. Basement membrane thickening and diabetic microangiopathy. Diabetes 1976; 25: 925-7.

8 Yue DK, McLennan SV, Turtle JR. Pathogenesis of diabetic microangiopathy: the roles of endothelial cell and basement membrane abnormalities. Diab Med 1992; 9: 218-20.

9 Spiro RG. Studies on the renal glomerular basement membrane. $\mathcal{F}$ Biol Chem 1967; 242: 1923-32.

10 Hagg E. Glomerular basement membrane thickening in rats with long-term alloxan diabetes. Acta Path Microbiol Scand 1974; 82: 211-9.

11 Siperstein MD, Unger RH, Madison LL. Studies of muscle capillary basement membranes in normal subjects, diabetic and prediabetic patients. F Clin Invest 1968; 47: 1973-99.

12 Friederici HHR, Tucker WR, Schwartz TB. Observations on small blood vessels of skin in normal and diabetic patients. Diabetes 1966; 15: 233-50.

13 Braverman IM, Sibley J, Keh A. Ultrastructural analysis of the endothelial-pericyte relationship in diabetic cutaneous endothelial-pericyte relationship in diabeti
vessels. F Invest Dermatol 1990; 95: 147-53.

14 Fischer F, Gartner J. Morphometric analysis of basal laminae in rats with long term streptozotocin diabetes. I Vitroretinal juncture. Exp Eye Res 1982; 34: 595-600.

15 Fischer F, Gartner J. Morphometric analysis of basal laminae in rats with long term streptozotocin diabetes. II Retinal capillaries. Exp Eye Res 1983; 37: 55-64.

16 Sosula L, Beaumont P, Jonson KM, Hollows FC. Quantitative ultrastructure of capillaries in rat retina. Invest Ophthalmol 1972; 11: 916-25.

17 Waber S, Meister V, Rossi GL, Mordasini RC, Riesen WF. Studies on retinal microangiopathy and coronary macroangiopathy in rats with streptozotocin-induced diabetes. Arch B Cell Pathol 1981; 37: 1-10.

18 Ashton N. Vascular basement membrane changes in diabetic retinopathy. BrF Ophthalmol 1974; 58: 344-66.

19 Gardiner TA, Archer DB. Fine structural changes in retinal vessels of experimental and spontaneously diabetic dogs. Doc Ophthalmol 1990; 76: 171.

20 Anderson HR, Stitt AW, Gardiner TA, Lloyd SJ, Archer DB. Induction of alloxan/streptozotocin diabetes in dogs: a revised experimental technique. Lab Animals 1993; 27: 281-5.

21 Kuwabara T, Cogan DG. Studies of retinal vascular patterns: Part 1 Normal architecture. Arch Ophthalmol 1960; 64: 904-11.

22 Engerman RL, Kern TS. Diabetic retinopathy: is it a consequence of hyperglycaemia? Diabetic Med 1985; 2: 200-3.
23 Engerman RL, Kern TS. Hyperglycemia as a consequence of diabetic retinopathy. Met Clin Exp 1986; 35 (suppl 1): 20-3.

24 Engerman RL, Kern TS. Is diabetic retinopathy preventable? Int Ophthalmol Clin 1987; 27: 225-9.

25 Beyer TA, Hutson NJ. Evidence for the role of the polyol pathway in the pathophysiology of diabetic complications. Metabolism 1986; 35: 1-3.

26 Buzney SM, Frank RN, Varma SD. Aldose reductase in retinal mural cells. Invest Ophthalmol Vis $S c i$ 1977; 16:392-6.

27 Kinoshita JH. Aldose redose in the diabetic eye. XLIII Edward Jackson memorial lecture. Am $\mathcal{F}$ Ophthalmol 1986; 102: 685-92.

28 Winegrad AI. Banting Lecture 1986. Does a common mechanism induce the diverse complications of diabetes? Diabetes 1986; 36: 396-406.

29 Brownlee M, Vlassara H, Cerami A. Nonenzymatic glycosylation and the pathogenesis of diabetic complications. Ann Intern Med 1984; 101: 527-37.

30 McVerry BA, Fisher C, Hopp A, Huehns ER. Production of pseudodiabetic renal glomerular changes in mice after repeated injections of glycosylated proteins. Lancet 1980; i: 738-40.

31 Tsilibary EC, Charonis AS, Reger LA, Wohlhueter RM, Furcht LT. The effect of nonenzymatic glycosylation on the binding of the main non-collagenous $\mathrm{NCl}$ domain to type IV collagen. $\mathcal{F}$ Cell Biol 1988; 262: 4302-8.

32 Brownlee M, Spiro RG. Glomerular basement membrane metabolism in the diabetic rat. Diabetes $1979 ; 28: 121-5$.

33 Lubec G, Pollak A. Reduced susceptibility of nonenzymatically glucosylated glomerular basement membrane to proteases: is thickening of glomerular basement membrane due to reduced proteolytic degradation? Renal Physiol 1980; 3: 4-8.

34 Steinberg M, Andre J, Peyroux J. Inhibition of the $\alpha$ glucosidase specific for collagen disaccharide units in diabetic rat kidney by in vivo glucose levels: possible contribution to BM thickening. Diabetologia 1983; 24: 286-9.

35 Spiro RG, Spiro MJ. Effect of diabetes on the biosynthesis of the renal glomerular basement membrane. Diabetes 1971; 20: 641-8.

36 Cohen MP, Khalif A. Effect of diabetes and insulin on rat renal glomerular protocollagen hydroxylase activities. Biochim Biophys Acta 1977; 496: 88-94.

37 Baynes JW. Role of oxidative stress in development of complications in diabetes. Diabetes 1991; 40: 405-12.

38 Ceriello A, Quatraro A, Giugliano D. New insights on nonenzymatic glycosylation may lead to therapeutic approaches for the prevention of diabetic complications. Diab Med 1992; 9: 297-9.

39 Gillery P, Monboisse JC, Maquart FX, Borel JP. Glycation of proteins as a source of superoxide. Diabete Metabolisme proteins as a source of
(Paris) $1988 ; 14: 25-30$.

40 Hunt JV, Dean RT, Wolff JP. Hydroxyl radical production and autoxidative glycosylation. Biochem $\mathcal{F}$ 1988; 256: 205-12.

41 Wolff SP, Dean RT. Glucose auto-oxidation and protein modification. The potential role of 'autoxidative glycosylation' in diabetes. Biochem $\mathcal{F} 1987$; 245: 243-50.

42 Oberley LW. Free radicals and diabetes. Free Rad Biol Med 1988; 5: 113-24.

43 Pournaras CJ, Riva CE, Tsacopoulos M, Strommer K. Diffusion of $\mathrm{O}_{2}$ in the retina of anaesthetized miniature pigs in normoxia and hyperoxia. Exp Eye Res 1989; 49: 347-60.

44 Lyons TJ, Thorpe SR, Baynes JW. Glycation and autoxidation of proteins in aging and diabetes. In: Ruderman $\mathrm{N}$, Williamson J, Brownlee $\mathbf{M}$, eds. Hyperglycemia, diabetes and vascular disease. New York, Oxford: Oxford University vascular disease. New
Press, 1992: 197-217. 